\title{
A Study on Effects of Regional Innovation Environment on Regional Development Outcome in 4th Industrial Revolution
}

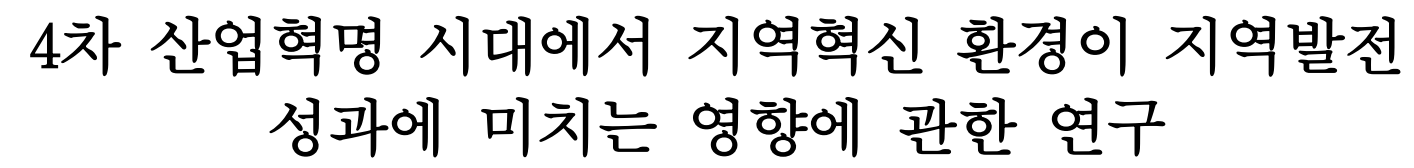

Jaebum Hong ${ }^{1}$, Changsun Yum², Jaekyun Jun ${ }^{3}$, Hakyun Kim ${ }^{4}$

홍재범 ${ }^{1}$, 염창선 ${ }^{2}$, 전재균 ${ }^{3}$, 김하균 ${ }^{4}$

${ }^{1}$ Professor, Division of Business, Pukyong National University, Korea, jbhong@pknu.ac.kr

${ }^{2}$ Professor, Division of Business, Pukyong National University, Korea, yumcs@pknu.ac.kr

${ }^{3}$ Professor, Division of Business, Pukyong National University, Korea, jkjun@pknu.ac.kr

${ }^{4}$ Professor, Division of Business, Pukyong National University, Korea, kimhk@pknu.ac.kr

Corresponding author: Hakyun Kim

\begin{abstract}
It can be said that the 4th industrial revolution is essential for regional development as it has a profound impact on society, economy and business. This 4th industry can innovatively develop the region. Various start-up companies around the world are growing into global companies and there is a lot of interest in wanting to become leaders of these companies. Analysis of society as a whole using big data has been attempted from a different perspective and is becoming an issue. Services founded on the artificial intelligence and Internet of Things are being introduced worldwide. As this paradigm shift is rapidly increasing, the speed of change is rapidly increasing. In order to achieve regional development results, changes in the local innovation environment will have a profound impact. The purpose of this research is to investigate the association between regional growth creation and regional development performance on the regional innovation environment. For questionnaire analysis, SPSS 22.0, a statistical package, was used for basic statistical analysis. Hypothesis testing was performed using the structural equation package Smart PLS 2.0. Factors that determine the regional innovation environment are divided into startup discovery, big data connection, and IOT technology infrastructure creation. A summary of the study follows. First, the discovery of startups had a significant effect on the creation of regional growth. Second, big data linkage had a significant effect on regional growth creation. Third, the establishment of the IOT technology base had a significant effect on the creation of regional growth. Fourth, regional growth creation had a significant effect on regional development performance.
\end{abstract}

Keywords: External Environment, Internal Environment, Public Sector Environment, Opportunity Seizing, Process Improvement

요약: 제 4 차 산업혁명은 주요 산업, 경제, 사회의 변화를 의미하며, 그 의미가 지속해서 확장되고 있다. 지역발전을 위해서는 4차산업의 도입이 필수적이라고 할 수 있다. 이는 벌써 사회, 경제 및 기업에 지대한 영향을 주고 있다. 이러한 4차산업은 지역을 혁신적 으로 발전시킬 수 있다. 세계적으로 다양한 스타트업 기업이 글로벌기업으로 성장하고 이러한 기업의 리더십에 지대한 관심이 쏠리고 있다. 빅데이터를 이용한 사회 전체의 분

Received: June 15, 2021; $1^{\text {st }}$ Review Result: July 30, 2021; $2^{\text {nd }}$ Review Result: September 15, 2021 Accepted: October 31, 2021 
석은 다른 시야에서 시도되어 이슈가 되고 있다. 사물인터넷과 인공지능을 기반으로 하 는 서비스들이 세계적으로 도입되고 있다. 이러한 패러다임의 전환이 급격해지면서 변화 의 속도가 급속도로 증가하고 있다. 지역발전성과를 이루기 위해서는 지역혁신환경의 변 화가 지대한 영향을 미칠 것이다. 연구의 목적은 지역혁신환경에서 지역성장창출과 지역 발전성과의 영향관계를 분석하고자 한다. 설문지 분석을 위해 기본통계분석을 위해 통계 패키지인 SPSS 22.0을 사용하였다. 구조방정식 패키지 Smart PLS 2.0을 사용하여 가설검 정을 실시하였다. 지역혁신환경을 결정하는 요인으로 스타트업 발굴, 빅데이터 연계, IOT 기술기반조성으로 나누었다. 연구의 요약은 다음과 같다. 첫째, 스타트업 발굴은 지 역성장창출에 유의한 영향을 미쳤다. 둘째, 빅데이터 연계는 지역성장창출에 유의한 영 향을 미쳤다. 셋째, IOT 기술기반조성은 지역성장창출에 유의한 영향을 미쳤다. 넷째, 지역성장창출은 지역발전성과에 유의한 영향을 미쳤다.

핵심어: 스타트업 발굴, 빅데이터 연계, IOT 기술기반조성, 지역성장창출, 지역발전성과

\section{1. 서론}

4차 산업혁명은 주요 산업, 경제, 사회의 변화를 의미하며, 그 의미가 지속해서 확장되고 있다. 이러한 변화는 로봇공학, 금융, 제조, 개인비서 및 콘텐츠를 포함한 다양한 영역에서 이미 진행 중이다. 이러한 영역은 사물인터넷, 인공지능, 빅데이터, 클라우드 컴퓨팅 및 혼합현실 등의 첨단 정보통신기술이 융합된 지능형 기술을 통하여 실현된다. 기존 산업의 업그레이드, 산업 간 융합 및 새로운 산업 창출을 위한 새로운 기회를 제공할 것이다. 사물인터넷(Internet of Thing; IoT)에서 인공지능의 활용은 서비스 공간의 사용자 접근성과 확장성을 제공한다. 4 차 산업혁명은 인간 친화적이고 몰입적인 인터페이스 및 콘텐츠 기술과 결합 되어 있다. 4차 산업혁명 시대에서 사람이 이해하기 어려운 분야는 첨단 지능형 기술로 실현될 것이다. 이러한 모든 것이 네트워크로 연결된 사물인터넷은 물건을 생산하거나 판매하는 운영자가 주도하지 않는다. 사물, 지능 및 서비스에 대한 사용자의 접근을 관리하는 운영 주체가 주도권을 갖는다. 지역발전을 위해서는 4차 산업혁명의 도입이 필수적이라고 할 수 있다. 이는 벌써 사회, 경제 및 기업에 지대한 영향을 주고 있다. 이러한 4 차산업은 지역을 혁신적으로 발전시킬 수 있다.

세계적으로 다양한 스타트업 기업이 글로벌기업으로 성장하고 이러한 기업의 리더십에 지대한 관심이 모아지고 있다. 스타트업 기업에 대한 도전이 계속 진행되고 있다[1]. 빅데이터를 이용한 사회전체의 분석은 다른 시야에서 시도되어 이슈가 되고 있다. 여러 산업분야에 걸쳐 인공지능, 사물인터넷, 정보통신기술 등을 활용한 변화가 이루어지고 있다. 사물인터넷과 인공지능을 기반으로 하는 서비스들이 세계적으로 도입되고 있다. IoT와 AI가 도입되면서 제품의 작동을 제어할 수 있으며, 제품과 서비스가 과거와는 차별적으로 융합되는 것이다. 이러한 패러다임의 전환이 급격해지면서 변화의 속도가 급속도로 증가하고 있다.

본 연구는 지역혁신 환경요인(스타트업 발굴, 빅데이터 연계, IOT 기술기반조성)이 지역성장창출과 지역발전성과에 어떤 영향을 줄 것인지를 실증적으로 분석한 연구이다. 지역발전성과를 성취하기 위한 방법으로 스타트업 발굴, 빅데이터 연계, IOT 
기술기반조성으로 설정하였다. 이는 지역성장을 창출하고, 결과적으로 지역발전에 큰 공헌을 할 것이다. 지역발전성과를 이루기 위해서는 지역혁신환경의 변화가 매우 필요하다.

\section{2. 이론적 배경}

\section{1 지역혁신 환경요인}

다양한 연구에서 외부환경 요인을 기술 변동성, 산업경쟁의 강도 및 시장성장률과 같은 변수를 중요하게 간주한다. 많은 연구에서 기술변동성과 산업경쟁력은 기업의 성과에 중대한 영향을 미치는 것으로 밝혀졌다. 하지만 4차 산업혁명과 지능형 기술을 도입한다면 외부환경 요인이 달라진다. 현재의 지역 환경은 급속한 환경의 변화이다. IT산업의 발전으로 인해 4차 산업혁명과 지능형 기술이 급진적으로 빠르게 변화하고 있다. 이러한 변화는 지역혁신환경을 위해 필수적이며, 지역발전성과를 위해서도 필요하다. 따라서 4차 산업혁명을 위한 지역혁신환경을 스타트업 발굴, 빅데이터 연계, IOT 기술기반조성으로 분류하였다.

스타트업 발굴: 스타트업은 창업한 지 얼마 안 된 벤처기업이다. 혁신적 기술과 아이디어를 보유한 새로운 창업기업이지만 자금의 어려움을 갖고 있다. 시장의 불확실한 환경에서 신생 제품, 아이디어, 서비스를 창출하기 위해 고안된 기관으로 혁신적인 기술을 가지고 있다. 하지만 기업 규모가 작고, 자본이 부족하여 사업이 안정적으로 되는 데 시간이 필요하다. 또한, 사업 내용이 단순하여 창출한 비즈니스 모델을 새롭게 개발하기 위한 투자가 어렵다. 투자가 어렵기 때문에 경쟁우위를 갖고도 생존하기 힘들다. 한국의 경우 정부 차원에서 창업지원 포털을 통하여 꾸준히 지원되고 있다. 따라서, 스타트업 창업의 여건은 지속해서 좋아지고 있다. 스타트업의 수가 매년 증가하고 있으며, 생존확률은 높지 않은 특성이 있다. IT 스타트업과 같이 기술 위주의창업은 창업은 가능하나, 창업 후 기술의 중요성보다 자금 부족 등의 이유로 실패하는 경우가 많다[2]. 기업의 존속 자체가 자금 부족으로 인한 위험은 내부 및 외부의 상황을 적절히 고려하여야 한다. 다양한 위험 속에서 지속적인 성장과 성과를 창출해서 유사산업속에서 경쟁우위를 차지해야 한다.

빅데이터 연계: 현재 사회과학, 인공지능, 정보통신분야 등의 모든분야에서 4 차 산업혁명의 시작과 더불어 빅데이터에 지대한 관심을 두고 있다[3]. 빅데이터를 활용하고자 하는 접근방법이 모든 학문분야에서 이슈가 되고 있다. 다양한 주제가 빅데이터 처리방식 및 분석 기법에 따라 결과가 달라진다. 다양한 시도 중 사회과학 분야에서는 텍스트 분석을 위한 자동화된 텍스트 내용 분석의 연구에 집중되고 있다. 국내에서도 빅데이터를 사용한 자동화된 텍스트 내용의 분석 연구가 등장하고 있다. 정부는 데이터산업의 중요성을 알고 있으며, 다양한 지원정책을 펼쳐 왔다. 그러나 해외에 비해 산업의 활성화 추진이 늦은 상태이다. 빅데이터 산업의 의미는 기업과 국가에 큰 영향을 줄 정도로 중요성이 크다. 정부는 빅데이터를 활용하여 정책 간에 우선순위를 정하고, 다양하게 나타나고 있는 빅데이터 산업의 병목 현상을 해소해야 한다. 빅체이터를 통하여 산업과 지역을 발전시키기 위해서는 필요한 효과들을 창출해야 한다. 해당 산업과 지역에 적합한 정책 설계가 반드시 필요하다. 빅 데이터를 산업 분야에서 적용할 수 있도록 빅데이터의 연구와 정책이 필요하다. 
IOT 기술기반조성: 최근 사물인터넷(Internet of Things) 기술은 공공시설, 산업 환경뿐만 아니라 일반 사용자의 일상생활에도 활용되고 있다. 이러한 가정용 IOT 기술의 장점은 단순한 편리함을 넘어 사용자의 환경과 니즈에 맞추어 개인화된 경험을 제공하는 것에 있다[4]. 이에 따라 사용자가 직접 IoT 환경을 구축하도록 돕는 DIY(Do-ityourself) 방법과, DIY 및 IoT 환경에서의 사용자 경험에 대한 연구가 수행되었다. 대형 가전 중심의 기성 제품들은 익숙하고 수요가 많기 때문에 IoT 기술에 대한 접근성 역시 높다. 대다수의 일반 사용자들에게 만족스러운 IoT 경험을 제공하기 위해서는 IoT 기능이 포함된 기성 제품의 체계적인 사용자 경험 디자인이 필요하다. 사물인터넷은 스마트 엔터테인먼트, 스마트 자동차, 스마트 홈, 스마트 헬스까지 소비자가 가까이 느낄수 있다. 또한 소비자 입자에서는 사물인터넷 제품은 원하는 정보 쉽게 얻을 수 있음으로 사용량이 지속해서 늘어날 것으로 예측된다. IOT를 활용한 웨어러블 디바이스의 급성장은 다양한 기업들의 성장이 기대된다. IOT에 대한 활용도가 소비자 행동 측면과 연결되어 연구가 진행되고 있다. 소비자가 IOT를 소비한다는 것은 또 다른 새로운 소비생활을 의미한다.

\section{2 지역성장창출}

지역 성장 창출이란 국가 내의 특정 지역에서 지역발전에 필요한 정책, 인적, 물적 기반을 조성하는 것이다[5]. 특정 지역에서 문제를 해결하기 위한 총체적 노력과 지역의 발전과 복지를 향상하는 것이다. 지역 성장을 위한 지역의 경제적인 발전과 복지향상을 위한 사회발전의 개념을 내포한다. 지역 성장 창출은 궁극적으로 지역발전과 연결되어 있다. 지역 성장 창출은 지역경제, 지역복지, 지역문화 등의 지역의 모든 분야에 맥락을 같이한다. 전반적으로 지역 성장 창출의 개념은 경제, 역사, 문화를 총체적으로 의미한다. 지역 성장 창출의 의미는 도시와 다른 지역과 약간의 차이를 보이기도 하는데, 지역을 발전시키기 위한 자원의 기반조성을 원칙으로 하고 있다.

\section{3 지역발전성과}

지역발전성과는 지역 성장과 지역경제의 활성화와 맥락을 같이 한다. 지역발전의 성과를 얻기 위해서는 지역경제를 활성화하기 위한 4차 산업혁명에 대한 노력이 필요하다. 이를 위해 스타트업 기업이나 빅데이터, 사물인터넷 등의 지역경제를 활성화하기 위한 전략이 중요하다. 이는 지역경제의 활성화와 활성화로 인한 결과로 지역주민의 일자리 증가, 지역주민의 소득을 증진할 수 있다[6]. 수도권보다 낙후된 지역에 지역발전을 위해서는 4차 산업혁명의 창조적인 전략을 가져야 한다. 이는 스타트기업 및 기업의 유치와 일자리 창출에 기여 할 수 있을 것이다. 기본적으로 지역 성장을 위한 외생적 지역발전 정책은 지방자치단체나 국가와 같은 외부 세력에 의한 발전의 동력을 찾고 있다. 하지만 적극적인 지역발전 기업과 주민의 참여와 교육으로 지역경제를 활성화하는 데 초점을 둔다. 4차 산업혁명에 대한 지역기업과 참여가 성공의 중요한 기회가 되는 것이다. 4차 산업혁명에 대한 지역 발전 정책은 관련 산업의 발전을 가지고 온다. 


\section{3. 연구 설계}

\section{1 연구모형}

본 연구는 4차 산업혁명 시대에서 지역혁신환경 요인이 지역성장창출 및 지역발전성과에 어떠한 영향을 미치는지를 실증적으로 측정하고 분석하는데 의의가 있다. 기존의 연구를 기반으로 지역혁신환경 요인은 스타트업 발굴, 빅데이터 연계, IOT 기술기반조성 정의하였다. 연구모형은 [그림 1]과 같다.

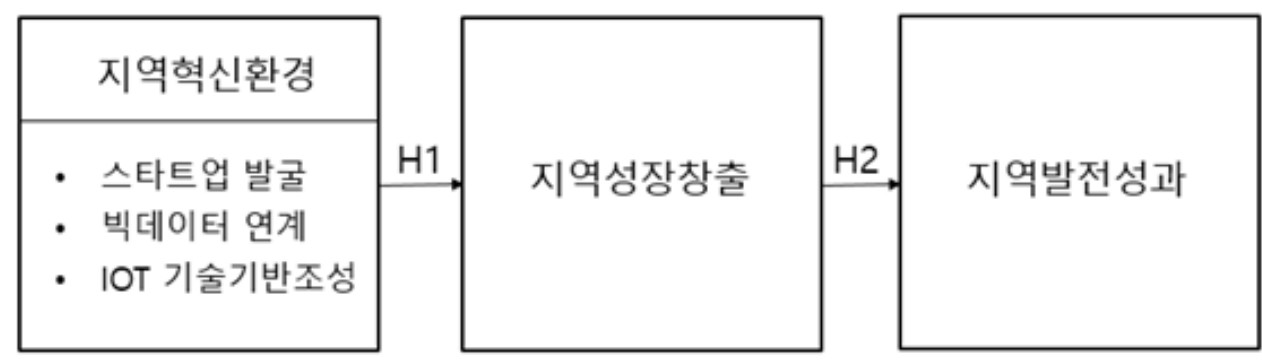

[그림 1] 연구모형

[Fig. 1] Research Model

\section{2 연구 가설}

기존 연구에서 지역성장창출 및 지역발전성과에 관한 다양한 연구가 독립적으로 진행됐다. 그러나 지능형 기술인 4차 산업혁명 시대를 능동적으로 대처하는 지역혁신환경 요인, 지역성장창출 및 지역발전성과에 관한 연구는 매우 드물다. 지능형 기술을 지역혁신환경에 응용하는 정의는 연구자마다 다르며 또한 매우 다양하게 정의되고 있다. 4차 산업혁명 시대를 대표하는 지역혁신환경 요인 중에서, 본 연구에서는 스타트업 발굴, 빅데이터 연계, IOT 기술기반조성으로 정의하였다. 지역성장창출을 위해 스타트업의 관점에서 벤처캐피털과의 관계가 매우 중요하다[7]. 빅 데이터를 이용한 지역발전방법에서 전문가와 지역현실에 적용 가능성을 도출하고자 했다[8]. 구체적으로 지역발전 지표를 위해 빅데이터 전문가, 지역사회에 특화된 전문가, 현장 중심형 전문가 등에 대해 의견을 조사한 후에 수도권의 빅데이터 전문가와 비교하는 것이다. 사물인터넷(IoT)은 일상생활에서 무선통신기술을 사용하여 인터넷을 통해 사람과 사물을 양방향으로 연결하는 것이다[9]. 선행연구를 기반으로 다음과 같은 가설이 설정되었다.

가설 $\mathrm{H} 1 ; 4$ 차 산업혁명 시대에서 지역혁신 환경요인이 지역성장창출에 유의한 영향을 미친다.

가설 H1-1; 스타트업 발굴은 지역성장창출에 유의한 영향을 미친다.

가설 H1-2; 빅데이터 연계는 지역성장창출에 유의한 영향을 미친다.

가설 H1-3; IOT 기술기반조성은 지역성장창출에 유의한 영향을 미친다.

지역경제의 성과를 위해서는 지역의 성장동력의 창출이 근간이 된다고 했다[10]. 특히 
이중에서 지역발전의 성과 중에서 특허출원의 비중은 지역대학이 수도권 대학에 비해 비율이 높았다. 대학으로부터의 벤처기업이 신기술 이전도 지역대학의 비중이 높았다

가설 $\mathrm{H} 2 ; 4$ 차 산업혁명 시대에서 지역성장창출이 지역발전성과에 유의한 영향을 미친다.

\section{3 설문조사 및 통계처리방법}

본 연구에서 측정항목은 기존연구에서 사용하였던 설문 문항을 본 연구의 취지에 맞게 재구성하여 사용하여 각 문항을 Likert 5점 척도(scale)로 측정하였다. 설문지의 기본통계분석을 위해 통계 패키지인 SPSS 22.0을 사용하였다. 가설검정을 위해 구조방정식 패키지 Smart PLS 2.0을 사용하여 집중타당성과 판별타당성을 검증하였다. 요인로딩 값, Cronbach' a 및 구성신뢰도 (Composite Reliability) 및 각 요인의 평균분산추출 값 (Average Variance Extraction)을 검증했다. 0.6 이상의 요인적재 값, Cronbach' a 값은 0.7 이상, 구성신뢰도 값은 0.7 이상, 및 0.5 이상의 분산추출지수 값이 일반적으로 유효한 것으로 간주된다.

\section{4. 실증분석 및 결과}

\section{1 자료수집 및 표본의 특성}

본 연구에서는 지역발전성과를 측정하기 위하여 4차산업혁명에 대한 의견을 구하고자 지역내에서 4 차산업관련 전문가들에 대하여 심층적으로 설문조사를 실시했다. 구체적으로 4 차산업 관련 교육과정을 운영, 정부 및 공공 분야 4 차산업 연구, 4 차산업 관련 산업계 종사자, 기타 종사자 등 56명으로 구성하였다. 설문조사는 2021년 3월 1 일부터 3 주간 진행하였다. 설문조사 대상인 4차산업에 종사하는 전문가는 남자 $67 \%$, 여성 33\%, 연령대는 30대 미만 9\%, 40대 미만 56\%, 50대 미만 20\%, 50대 이상 $15 \%$ 이다. 종사분야는 교육 $25 \%$, 연구 $35 \%$, 사업 분야 $40 \%$ 에 종사하는 전문가를 대상으로 하였다.

\section{2 자료의 분석}

설문지의 정확성을 위해 신뢰성과 타당성분석이 [표 1]과 [표 2]에 표시되어 있다. 신뢰성은 Cronbach's a 가 0.7이상으로 문제가 없다. 집중타당성은 요인 적재값 0.6, 구성신뢰도 $0.7, \mathrm{AVE}$ 값이 0.5 이상으로 문제가 없다. 판별타당성은 $\mathrm{AVE}$ 의 제곱근값이 상관계수의 종과 횡의 값보다 크므로 문제가 없다.

[표 1] 신뢰도 및 집중 타당성 분석결과

[Table 1] Reliability and Internal Consistency Results

\begin{tabular}{|c|c|c|c|c|}
\hline \multirow{2}{*}{ 변수 } & 요인적재 값 & AVE & C. R. & Cronbach's a \\
\hline \multirow{3}{*}{ 스타트업 발굴 } & 0.738 & \multirow{2}{*}{0.638} & 0.841 & 0.717 \\
\cline { 1 - 2 } & 0.782 & \multirow{2}{*}{0.829} & & 0 \\
\cline { 1 - 2 } & & & & \\
\hline
\end{tabular}




\begin{tabular}{|c|c|c|c|c|}
\hline \multirow{5}{*}{ 빅데이터 연계 } & 0.725 & \multirow{5}{*}{0.623} & \multirow{5}{*}{0.891} & \multirow{5}{*}{0.848} \\
\hline & 0.782 & & & \\
\hline & 0.832 & & & \\
\hline & 0.831 & & & \\
\hline & 0.771 & & & \\
\hline \multirow{3}{*}{ IOT 기술기반조성 } & 0.786 & \multirow{3}{*}{0.612} & \multirow{3}{*}{0.825} & \multirow{3}{*}{0.787} \\
\hline & 0.783 & & & \\
\hline & 0.778 & & & \\
\hline \multirow{4}{*}{ 지역성장창출 } & 0.683 & \multirow{4}{*}{0.579} & \multirow{4}{*}{0.785} & \multirow{4}{*}{0.735} \\
\hline & 0.622 & & & \\
\hline & 0.690 & & & \\
\hline & 0.766 & & & \\
\hline \multirow{4}{*}{ 지역발전성과 } & 0.849 & \multirow{4}{*}{0.732} & \multirow{4}{*}{0.916} & \multirow{4}{*}{0.878} \\
\hline & 0.842 & & & \\
\hline & 0.856 & & & \\
\hline & 0.875 & & & \\
\hline
\end{tabular}

[표 2] 상관관계 및 판별타당성 분석결과

[Table 2] Correlation and Discriminant Validity

\begin{tabular}{|c|c|c|c|c|c|c|}
\hline 변수 & AVE & 1 & 2 & 3 & 4 & 5 \\
\hline 스타트업발굴 & 0.638 & 0.798 & & & & \\
\hline 빅데이터 연계 & 0.623 & 0.725 & 0.789 & & & \\
\hline IOT 기술기반조성 & 0.612 & 0.484 & 0.592 & 0.782 & & \\
\hline 지역성장창출 & 0.579 & 0.707 & 0.771 & 0.669 & 0.888 & \\
\hline 지역발전성과 & 0.732 & 0.699 & 0.699 & 0.497 & 0.688 & 0.855 \\
\hline
\end{tabular}

\section{3 연구모형의 검증}

구조모형은 Smart PLS 2.0을 사용하였으며 구조모형을 통해서는 연구모형의 변수들 간 의 경로계수와 결정계수(R2)결과 값을 도출하였다. R2값이 0.26 이상이면 적합도가 높은 편이며, $0.26 \sim 0.13$ 이면 중간이다. 0.13이하는 적합도가 낮은 것으로 표시할 수 있다[11 ]. 지역혁신환경(0.474)와 지역발전성과(0.700)에 대한 결정계수(R2)값은 상으로 나타났 다.

제한한 가설 $\mathrm{H} 1, \mathrm{H} 2$ 는 채택되었다. 첫째, 가설 $\mathrm{H} 1-1$ 의 “스타트업 발굴은 지역성장창출에 영향을 미친다” 라는 가설은 채택되었다. 스타트업 발굴은 지역성장창출 $(\beta=0.276, t=3.199, p<0.05)$ 에 유의한 영향을 미치는 것으로 나타났다. 이는 지역혁신 환경요인에서 스타트업 발굴은 지역성장창출에 영향을 준다는 것이다. 기존의 연구에서 스타트업의 성공을 위해서 초기 투자를 받은 벤처기업을 대상으로 중요도를 조사한 결과는 공정한 계약, 가치평가, 명성, 파트너 명성, 도움기대, 벤처캐피탈의 과거성과가 중요한 요소로 간주되었다[12]. 둘째, 가설 H1-2의 “빅데이터 연계는 지역성장창출에 영향을 미친다” 라는 가설은 채택되었다. 빅데이터 연계은 지역성장창출 $(\beta=0.390$, 
$\mathrm{t}=4.212, \mathrm{p}<0.05)$ 에 유의한 영향이 있는 것으로 나타났다. 이는 지역혁신 환경요인에서 빅데이터 연계는 지역성장창출에 영향을 준다는 것이다. 기존의 연구에서도 빅데이타를 통해 지역발전에 기여할 수 있다는 것이다[8]. 빅데이터 전문가의 역량과 그들의 교육방식이 지역발전에 영향을 준다는 것이다. 셋째, 가설 H1-3의 "IOT 기술기반조성은 지역성장창출에 영향을 미친다” 라는 가설은 채택되었다. IOT 기술기반조성은 지역성장창출 $(\beta=0.303, t=5.238, \quad \mathrm{p}<0.05)$ 에 유의한 영향을 미치는 것으로 나타났다. IoT 시대를 맞이하면서 개인이 소유하고 사용하는 정보통신기기의 수가 증가하고 있다 [13]. 대표적으로 스마트폰을 비롯한 각종 스마트 기기들이 대중화되면서 사물인터텟의 관심은 높아지고 있다. 넷째, 가설 $\mathrm{H} 2$ 의 "지역성장창출은 지역발전성과에 영향을 미친다” 라는 가설은 채택되었다. 지역성장창출은 지역발전성에 $(\beta=0.688, t=13.064$, $\mathrm{p}<0.05)$ 는 유의한 영향을 미치는 것으로 나타났다. 기술지식자본, 혁신노력, 기업가정신자본이 지역경제성과에 영향을 준다[8].

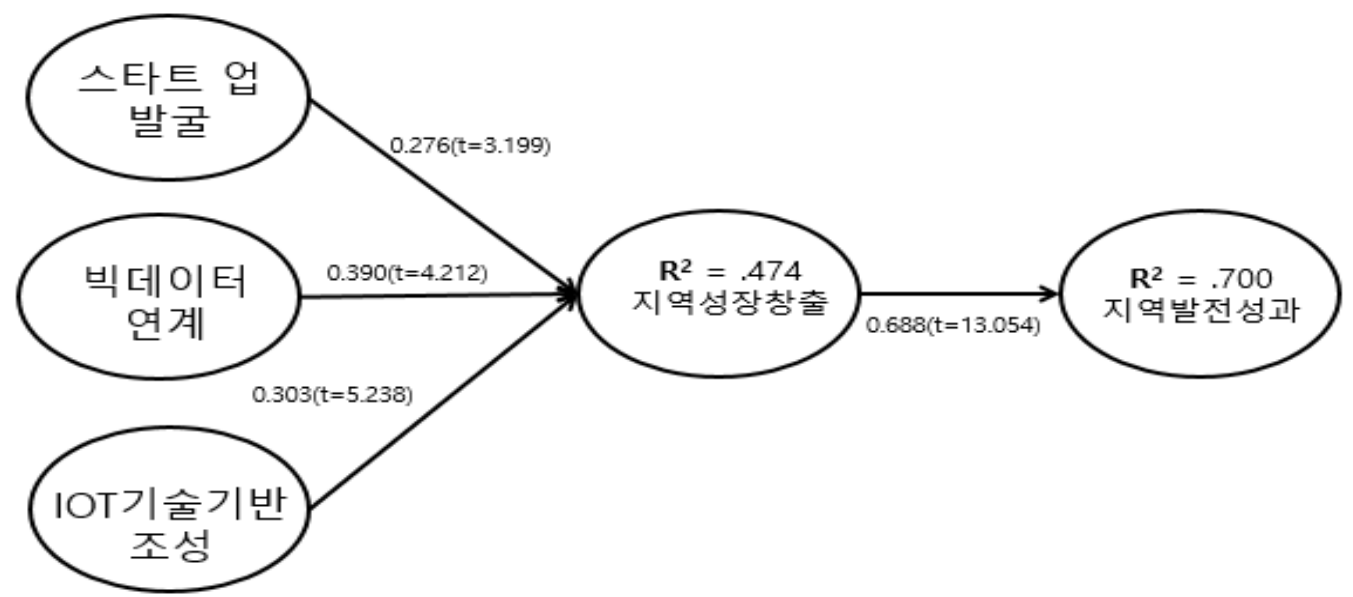

[그림 2] 구조모형 분석결과

[Fig. 2] The Results of Research Model

[표 3] 가설검정 결과요약

[Table 3] Results of Hypothesis Tests for the Research Model

\begin{tabular}{|c|c|c|c|}
\hline 가설 경로 & 표준화 계수 $(\beta)$ & t-value & 채택 유무 \\
\hline H1.1 스타트업 발굴 $\rightarrow$ 지역성장창출 & 0.276 & 3.199 & 채택 \\
\hline H1.2: 빅데이터 연계 $\rightarrow:$ 지역성장창출 & 0.390 & 4.217 & 채텍 \\
\hline H1.3 I0T 기술기반조성 $\rightarrow:$ 지역성장창출 & 0.303 & 5.238 & 채택 \\
\hline H2 지역성장창출 $\rightarrow$ 지역발전성과 & 0.688 & 13.064 & 채택 \\
\hline \multicolumn{2}{|l}{$\mathrm{t}=1.97 *, \mathrm{p}<0.05$} \\
\hline
\end{tabular}




\section{5. 결론}

본 연구에서는 지역혁신 환경(스타트업 발굴, 빅데이터 연계, IOT 기술기반조성)이 지역 성장 창출을 매개로 지역발전성과에 어떤 영향을 주는지 알아보기 위한 실증연구이다. 연구의 이론적 배경을 위해 지역혁신 환경, 지역성장창출, 지역발전성과에 대한 기존문헌을 정리하였다. 또한, 기존연구를 바탕으로 지역혁신환경, 지역 성장 창출, 지역발전성과에 대한 연구모형과 연구가설을 설정하였다. 본 연구의 실증분석 결과를 요약하면 다음과 같다. 첫째, 연구모형에서 지역혁신환경이 지역성장창출에 영향을 미친다는 가설 H1은 채택되었다. 스타트업 발굴, 빅데이터 연계 및 IOT 기술기반조성은 지역 성장 창출에 유의한 영향을 미쳤다. 둘째, 지역 성장 창출은 지역발전성과에 유의한 영향을 미쳤다는 가설 $\mathrm{H} 2$ 는 채택되었다.

본 연구의 성과와 기여도는 다음과 같다. 지역의 혁신적인 발전을 위한 지역혁신환경의 요소를 스타트업 발굴, 빅데이터 연계, IOT 기술기반조성으로 나누어 연구한 것이다. 지역을 발전시키기 위해서 또는 4차 산업혁명 시대에 정착하기 위해서는 4차산업 및 새로운 기술에 관한 변화의 연구가 필요한 시점이다. 4차 산업혁명 시대의 발전추세와 요구에 부응하기 위해서는 신 지능형 기술에 관한 실증적 연구가 필요하다. 지역의 발전을 위한 환경 적응을 위해서 4차 산업혁명 시대의 환경과 기술변화가 빠른 속도의 변화에 적응해야 한다. 이러한 변화에 능동적으로 대처하기 위해서는 지역 및 산업사회의 변화에 관한 지속적인 모니터링이 필요하다. 변화하는 환경 속에서 지역 성장 창출을 위해 4차 산업혁명 시대를 이해하고 환경 변화에 적극적으로 대응하는 것이 필수적이다.

본 연구의 한계는 표본의 사이즈가 56 개로 매우 적다는 것이다. 이는 SEM 검증에도 한계가 있다. 지역에 특화하기 위해 표본의 사이즈를 지역과 전문가를 중점으로 시도된 이유도 있지만 이를 일반화 시키기 위해서는 지역적 한계와 표본의 한계를 늘림으로 일반화시켜야 한다.

지역사회의 혁신을 위하여 특화한 전문가에 대해서는 본 연구 외에는 시도 자체가 없었다. 지역사회의 발전을 4 차산업혁명에 맞게 문제해결에 초점을 맞춘 연구는 시도된 사례가 없었고 성과를 발견하기도 어려운 실정이다. 전문가 심층 인터뷰는 로컬 스타트업, 빅데이터, 사물인터넷, 지역혁신문제 등 다양한 의견이 제시되었다.

기존의 연구에서는 지역혁신환경과 지역 성장 창출을 연관시킨 연구는 거의 없다. 이는 4 차 산업혁명 시대에서 지역혁신환경과 지역발전성과 연관시킨 논문이 중요하다는 의미임을 시사한다. 따라서 4 차 산업혁명 시대에서 지역발전을 위해서는 지역혁신환경의 경쟁력을 강화해야 한다. 4차 산업혁명 시대에서 지역을 발전시키기 위해서 다양한 지역발전전략이 마련되어야 한다. 본 연구는 지역이 변화하는 환경에서 지능형 기술을 이용하여 경쟁우위를 확보하기 위한 중요한 연구이다. 따라서 4 차 산업혁명 시대에서 지역혁신환경요인은 지역발전성과에 직접적인 영향을 미친다는 연구는 매우 중요하다. 따라서, 4 차 산업혁명 시대에서 생존하기 위해 지역발전에 대한 다양한 방법을 연구해야 한다.

\section{6. 감사의 글}

이 논문은 2021학년도 부경대학교 국립대학육성사업 지원비에 의하여 연구되었음. 


\section{References}

[1] D. T. Hall, Careers in and out of organizations, Thousand Oaks, CA: Sage, (2002)

[2] S. Hong, K. Serfes, V. Thiele, Competition in the venture capital market and the success of startup companies: Theory and evidence, Journal of Economics \& Management Strategy, (2020), Vol.29, No.4, pp.741-791. DOI : 10.1111/jems. 12394

[3] B. S. Xia, P. Gong, Review of business intelligence through data analysis, Benchmarking: An International Journal, (2014), Vol.21, No.2, pp. 300-311. DOI : 10.1108/BIJ-08-2012-0050

[4] C. Raddats, C. Kowalkowski, O. Benedettini, J. Burton, H. Gebauer, Servitization: A contemporary thematic review of four major research streams, Industrial Marketing Management, (2019), Vol.83, pp.207-223. DOI : 10.1016/j.indmarman.2019.03.015

[5] N. Fukugawa, Knowledge Spillover from University Research before the National Innovation System Reform in Japan: Localisation, Mechanisms, and Intermediaries, Asian Journal of Technology Innovation, (2016), Vol.24 No.1, pp.100122. DOI : $10.1080 / 19761597.2016 .1141058$

[6] M. Guerrero, J. A. Cunningham, D. Urbano, Economic Impact of Entrepreneurial Universities' Activities: An Exploratory Study of the United Kingdom, The Academy of Management Review, (2015), Vol.44, No.3, pp.748-764. DOI : 10.1016/j.respol.2014.10.008

[7] D. M. Cable, S. Shane, A prisoner's dilemma approach to entrepreneur-venture capitalist relationships, Academy of Management review, (1997), Vol.22, No.1, pp.142-176. DOI : 10.5465/AMR.1997.9707180262

[8] H. Choi, S. Lee, J. Kim, How to educate big data ?: Focusing on the design of a curriculum in the field of social science, Locality \& Communication (JLC), (2021), Vol.25, No.2, pp.27-45. DOI : 10.47020/JLC.2021.05.25.2.27

[9] D.Bandyopadhyay, J. Sen, Internet of things: Applications and challenges in technology and standardization, Wireless Personal Communications, (2011), Vol.58, No.1, pp.49-69. DOI : 10.1007/s11277-011-0288-5

[10] Y. Lee, Measures to foster local venture companies to create local new growth engines, Science and Technology Policy Institute, (2011), Vol.76, pp.1-25.

[11] J. Cohn, Statistical Power Analysis for the Behavioral Science(2nd), Lawrence Erlbaum Associates, pp.90-100, (1988)

[12] R. Vaidyanathan, V. Wadhwa, V. Vaidyanathan, Exploring Entrepreneurs' Perceptions of Venture Capitalists' Added Value, Journal of Macromarketing, (2019), Vol.39, No.4, pp.447-462. DOI : 10.1177/0276146719884610

[13] M. Park, S. Park, D. Lim, J. Lee, IoT Cloud Service Platform Business Case Study: SimPlatform, Korea Business Review, (2021), Vol.25, No.2, pp.75-89. 